\title{
Emerging Therapeutic Approaches to Combat COVID-19: Present Status and Future Perspectives
}

\author{
Karthik Vivekanandhan ${ }^{1}$, Poornima Shanmugam ${ }^{1}$, Hamed Barabadi ${ }^{2}$, \\ Vigneshwaran Arumugam ${ }^{3}$, Dharun Daniel Raj Daniel Paul Raj ${ }^{4}$, \\ Manikandan Sivasubramanian ${ }^{5}$, Subbaiya Ramasamy ${ }^{6}$, Krishnan Anand $^{7}$, Pandi Boomi ${ }^{8}$, \\ Balakumar Chandrasekaran ${ }^{9}$, Selvaraj Arokiyaraj ${ }^{10}$ and Muthupandian Saravanan ${ }^{11,12 *}$
}

OPEN ACCESS

Edited by: Binod Kumar

Loyola University Chicago, United States

Reviewed by:

Krishna Mohan Poluri, Indian Institute of Technology Roorkee, India

Atoshi Banerjee

University of Nevada, Las Vegas, United States

*Correspondence:

Muthupandian Saravanan bioinfosaran@gmail.com saravanan.muthupandian@mu.edu.et

Specialty section:

This article was submitted to Molecular Diagnostics and Therapeutics,

a section of the journal

Frontiers in Molecular Biosciences

Received: 09 September 2020 Accepted: 22 January 2021

Published: 08 March 2021

Citation:

Vivekanandhan $K$, Shanmugam $P$, Barabadi H, Arumugam V,

Daniel Raj Daniel Paul Raj D, Sivasubramanian M, Ramasamy $S$, Anand K, Boomi P, Chandrasekaran B, Arokiyaraj S and Saravanan M (2021) Emerging Therapeutic Approaches to Combat COVID-19: Present Status and Future Perspectives. Front. Mol. Biosci. 8:604447. doi: 10.3389/fmolb.2021.604447
${ }^{1}$ Department of Biotechnology, K. S. Rangasamy College of Technology, Tiruchengode, Tamilnadu, India, ${ }^{2}$ Department of Pharmaceutical Biotechnology, School of Pharmacy, Shahid Beheshti University of Medical Sciences, Tehran, Iran, ${ }^{3}$ School of Biosciences and Technology, Vellore Institute of Technology, Vellore, India, ${ }^{4}$ Department of Biotechnology, Maulana Abul Kalam Azad University of Technology, Haringhata, India, ${ }^{5}$ Department of Biotechnology, Saveetha School of Engineering, Saveetha Institute of Medical and Technical Sciences (SIMATS), Chennai, India, ${ }^{6}$ Department of Biological Sciences, School of Mathematics and Natural Sciences, The Copperbelt University, Riverside, Zambia, ${ }^{7}$ Department of Chemical Pathology, School of Pathology, Faculty of Health Sciences and National Health Laboratory Service, University of the Free State, Bloemfontein, South Africa, ${ }^{8}$ Department of Bioinformatics, Alagappa University, Karaikudi, India, ${ }^{9}$ Faculty of Pharmacy, Philadelphia University, Amman, Jordan, ${ }^{10}$ Department of Food Science and Biotechnology, Sejong University, Seoul, South Korea, ${ }^{11}$ Department of Microbiology and Immunology, Division of Biomedical Science, School of Medicine, College of Health Science, Mekelle University, Mekelle, Ethiopia, ${ }^{12}$ AMR and Nanomedicine Laboratory, Department of Pharmacology, Saveetha Dental College, Saveetha Institute of Medical and Technical Sciences (SIMATS), Chennai, India

Coronavirus disease (COVID-19) has emerged as a fast-paced epidemic in late 2019 which is disrupting life-saving immunization services. SARS-CoV-2 is a highly transmissible virus and an infectious disease that has caused fear among people across the world. The worldwide emergence and rapid expansion of SARS-CoV-2 emphasizes the need for exploring innovative therapeutic approaches to combat SARS-CoV-2. The efficacy of some antiviral drugs such as remdesivir, favipiravir, umifenovir, etc., are still tested against SARS-CoV-2. Additionally, there is a large global effort to develop vaccines for the protection against COVID-19. Because vaccines seem the best solution to control the pandemic but time is required for its development, pre-clinical/clinical trials, approval from FDA and scale-up. The nano-based approach is another promising approach to combat COVID-19 owing to unique physicochemical properties of nanomaterials. Peptide based vaccines emerged as promising vaccine candidates for SARS-CoV-2. The study emphasizes the current therapeutic approaches against SARS-CoV-2 and some of the potential candidates for SARS-CoV-2 treatment which are still under clinical studies for their effectiveness against SARS-CoV-2. Overall, it is of high importance to mention that clinical trials are necessary for confirming promising drug candidates and effective vaccines and the safety profile of the new components must be evaluated before translation of in vitro studies for implementation in clinical use.

Keywords: COVID-19, SARS-CoV-2, therapeutics, antiviral drugs, vaccines, nano-based approaches 


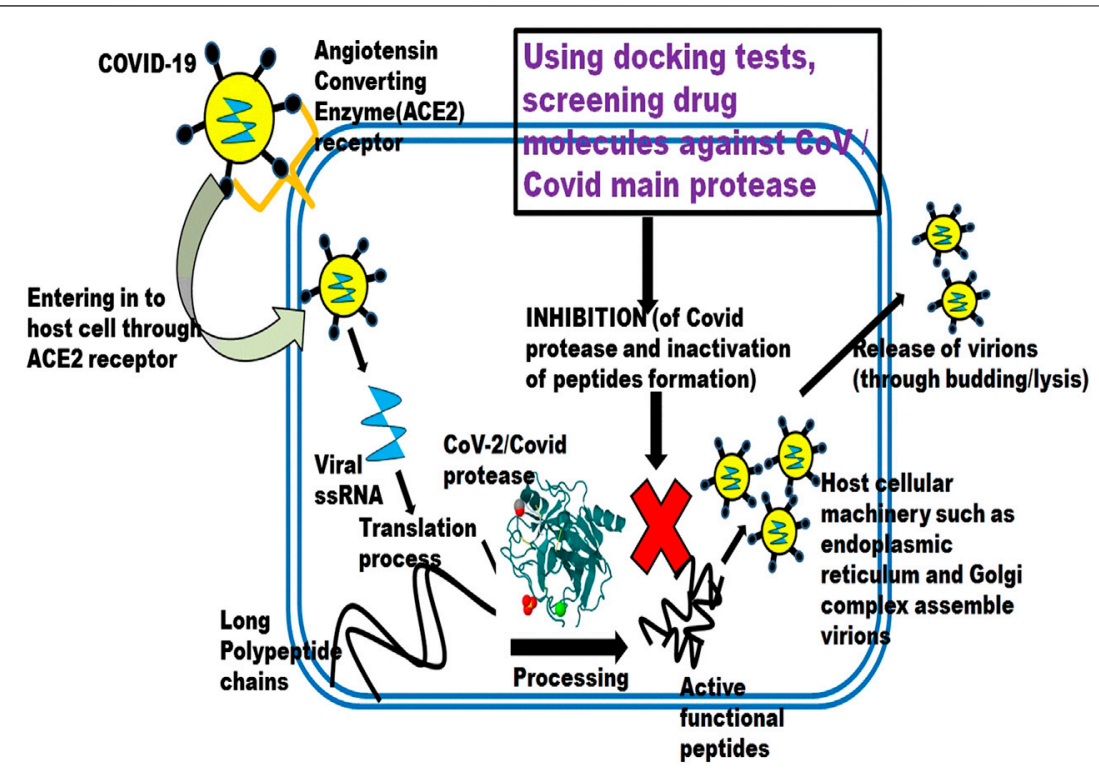

FIGURE 1 | A schematic illustration of drug repurposing approach.

\section{INTRODUCTION}

The COVID-19 outbreak made the entire world frightened in late 2019, which is caused by severe acute respiratory syndrome coronavirus-2 (SARS-CoV-2) belongs to single stranded RNA viruses having spike-like projections of glycoprotein. The virus infection was first reported in Wuhan, People's Republic of China during December 2019 (Chen et al., 2020). COVID-19 is the official name of the coronavirus declared by the World Health Organization (WHO). Even though the source of coronavirus has not been declared officially, bats and snakes are considered as the potential host. Wuhan institute of virology confirmed that $96 \%$ of similarity coronavirus with the gene sequence of bat coronavirus (Wang W. et al., 2020; Zhou P. et al., 2020). Coronavirus infects humans via the binding of S-protein with angiotensin-converting enzyme-2 (ACE-2) with higher affinity (Wrapp et al., 2020). Transmission of coronavirus is through respiratory droplets of infected persons. The common symptoms include fever, throat infection, cough, headache and breathlessness even some may be asymptomatic. The average incubation period of coronavirus ranges from three days to twenty-four days (Guan et al., 2020; Zhou et al., 2020a) but the prevalence is more in elderly people with medical comorbidities.

During this pandemic outbreak, several countries adopt preventive measures and their own treatment methodologies. Avoiding contact with infected persons, unnecessary travel and personal hygiene practices are the basic preventive measures followed to avoid the transmission of coronavirus. RT-PCR and chest computed tomography scan are the diagnostic tools used along with the combination of symptom relevant treatment (Velavan and Meyer, 2020). Viral infections are the major threat to the human kind. As of now, antiviral therapy, symptomatic and oxygen therapy are followed for treating SARS-CoV-2. Nano-based approaches are the promising tool for the diagnosis and treatment of such viral diseases. Based on the statistical analysis of StatNano, out of patents filed related to SARS-CoV-2 diagnostics and treatments, $5.2 \%$ belong to nanobased technology (Chakravarthy and Vora, 2020). With this background, the present review focuses on emerging approaches including drug repurposing, vaccine development including peptide and nano based approaches for COVID-19 therapeutics.

\section{EMERGING APPROACHES FOR COVID-19 THERAPEUTICS}

\section{Drug Repurposing Approach for COVID-19 Treatment}

Even though a lot of potential antiviral drugs are available, their efficacy against SARS-CoV-2 is still tested for implementation. Below discussed drugs are some of the potential candidates for COVID-19 treatment and are under clinical study. Figure 1 depicts the schematic illustration of drug repurposing approach.

\section{Remdesivir}

Remdesivir, developed by Gilead Sciences (2009), is a broadspectrum antiviral agent with a brand name of "veklury" administered as an intravenous injection. It was initially designed for Hepatitis C (Hep C) and respiratory syncytial virus (RSV). Later it was repurposed against Ebola and Marburg virus. Remdesivir has antiviral activity against filoviruses, pneumoviruses, paramyxoviruses, and coronaviruses in vitro (Lo and Jordan, 2017). Remdesivir, being an analogue of nucleotide, in its triphosphate form, i.e., Remdesivir triphosphate (RDV-TP), is used as a substrate for RNA dependent RNA polymerase, and has reported to inhibit the viral RNA synthesis by delayed termination of synthesis 
(Wang M. et al., 2020) in all corona viruses, including SARS$\mathrm{CoV}-2$. It was seen that RDV-TP resembles ATP (Adenosine triphosphate) (Saha et al., 2020). It competes with viral RNA synthesis, by forming a phosphodiester bond with the next nucleotide and terminates viral RNA formation at the third site from RDV-TP binding site, causing the termination of viral RNA synthesis in SARS-CoV-2 (Gordon et al., 2020).

Remdesivir exhibited an in vitro activity against SARS-CoV-2 in a preclinical study using Rhesus macaque model of SARS-CoV2, the treatment was initiated soon after the Rhesus macaque was inoculated with SARS-CoV-2, and group of Rhesus macaque treated with remdesivir showed lower virus levels than untreated (Williamson et al., 2020). The toxicity and adverse effect of remdesivir is not clear yet and is to be investigated further (Fan et al., 2020). In clinical trials, remdesivir does not show gastrointestinal toxicity apart from minor diarrhoea in a few cases. In case of hepatotoxicity, elevations in the aminotransferases were noticed. In the case of nephrotoxicity, upon continual doses of remdesivir, reduced kidney function was observed. In case of respiratory toxicity, acute respiratory syndrome was observed in $4 \%$ of the patients treated with remdesivir.

The recommendation for the use of remdesivir arose from the multicentre, randomized placebo-controlled trials and the adaptive SARS-CoV-2 treatment trial (ACTT) (Wang M. et al., 2020). The study was conducted across 1603 SARS-CoV-2 infected patients. The patients in the trial group were affected to an extent that they require oxygen supplement, but mechanical ventilation (ECMO) is not required and the recovery period of 10-15 days was observed (Beigel et al., 2020). It is currently approved for treatment in the United States, India, Taiwan, Singapore and many other countries.

\section{Hydroxychloroquine}

Chloroquine is an anti-malarial drug developed in 1934. Later in 1946 hydroxychloroquine (HCQ), an analogue of chloroquine was developed to treat autoimmune diseases. HCQ has been used for the treatment of lupus, erythematosus, Q fever, certain types of malaria and rheumatoid arthritis (American society of health system pharmacist 2020). HCQ has fewer and less severe toxicities (including less propensity to prolong the QTC interval) and fewer drug-drug interactions than chloroquine. Studies show that HCQ increases the endosomal $\mathrm{pH}$ inhibiting fusion of SARS-CoV-2 with the host cell membrane (Wang M. et al., 2020). They possess an immunomodulatory effect and also block the transport of SARS-CoV-2 from early endosomes to endolysosomes, which may be required for the release of viral genome (Liu et al., 2020).

Most deaths in SARS-CoV-2 patients occurred due to cytokine storms. Cytokines play an important role in normal immune responses, but releasing large amounts in the body all at once can be harmful. A cytokine storm can occur as a result of an infection, autoimmune condition, or other diseases. It is observed that HCQ can reduce cytokine storms (Cao, 2020). A recent study by Tang et al., (2020b) reported that HCQ reduced clinical symptoms through anti-inflammatory properties and recovery of lymphopenia. But still safety, side effects and effectiveness of HCQ are under study. Further, the benefits and risks associated with HCQ depends on patient medical history (Juurlink 2020).

FDA has approved the use of $800 \mathrm{mg}$ (HCQ) on the first day, followed by $400 \mathrm{mg}$ for the next seven days for COVID-19 treatment (US FDA - Hydroxychloroquinone fact sheet for patients). Higher dosage leads to arrhythmia and sometimes eventual death (Borba et al., 2020). Patients with a history of renal and liver disorders should be treated with care using HCQ as it leads to nephrotoxicity and hepatotoxicity (Rismanbaf and Zarei, 2020).

\section{Lopinavir/Ritonavir}

Lopinavir/Ritonavir, under the brand name Kaletra ${ }^{\circledR}$, belong to the protease inhibitor class which is especially used in the treatment of retroviruses which helps in SARS-CoV-2 treatment (Rismanbaf and Zarei, 2020). Although it is not curing HIV, it prevents secondary infections by decreasing the viral count, which are the characteristic symptoms of acquired immune-deficiency syndrome. Replication of SARS-CoV-2 depends on the cleavage of a poly protein into a RNAdependent RNA polymerase and helicase, which helps in replicating the viral genome in the host cells (Zumla et al., 2016). For the cleavage of the poly protein, two proteases enzymes including 3-chymotrypsin-like protease (3CLpro) and papain-like protease (PLpro) are responsible, found in SARSCoV-2 (Tahir ul Qamar et al., 2020). Thus, protease inhibitors like lopinavir and ritonavir reduce the viral count in the infected person's body system and help them in recovery. In an In vitro study, it was found that lopinavir/ritonavir inhibited the protease 3CLpro (Liu and Wang, 2020; Liu et al., 2020).

In a clinical research study with a sample size of 199 patients, the patients were given Lopinavir 400/Ritonavir $100 \mathrm{mg}$ orally, twice a day. It was observed that the group which was under liponavir/ritonavir treatment, recovered with a shorter intensive care time rather than the untreated group, and also the rate of mortality was less, though it was not statistically significant (Cao et al., 2020). Most clinical studies that surround lopinavir and ritonavir have a very small sample size, but it has been approved for treatment by National institute of Health (NIH) United States. The use of lopinavir/ritonavir is not recommended for patients suffering from porphyria, cardiac problems and cardiac conduction problems. Other side effects on usage are diarrhoea, which might persist for a week after usage. In some cases, diabetes mellitus, pancreatitis and hepatic problems have been reported as side effects due to the administering of lopinavir/ ritonavir (Joint Formulary Committee, 2020).

\section{Umifenovir}

Umifenovir, developed in Russia and China has been used for infections caused by Influenza A, B and prophylaxis. The main mode of action by umifenovir is blocking the fusion of virus to the cell/endosome by interfering with the hydrogen bond network in the phospholipid (Villalain, 2010). In vitro study on the effect of Umifenovir against SARS-CoV-1 and SARS-CoV-2 revealed that Umifenovir combined with protease inhibitor (Liponavir/ Ritonavir) exhibited higher negative conversion rates (Deng 
TABLE 1 | Mode of action of potential antiviral drugs repurposed for COVID-19.

\begin{tabular}{|c|c|c|}
\hline Drug & Mode of action & References \\
\hline Remdesivir & $\begin{array}{l}\text { Binds to the viral-RNA dependent RNA polymerase, inhibiting the replication of the virus by terminating transcription of } \\
\text { viral-RNA }\end{array}$ & Wit, (2020) \\
\hline Hydroxychloroquine & Increases the endosomal pH inhibiting the fusion of SARS-CoV-2 with the host cell membrane & Tang et al. (2020a) \\
\hline Lopinavir/Ritonavir & $\begin{array}{l}\text { Inhibits the protein } 3 C L \text { pro, required for cleaving poly protein into RNA dependent RNA polymerase and helicase, helps in } \\
\text { transcription of Viral RNA. }\end{array}$ & Cao et al. (2020) \\
\hline Umifenovir & Blocks the fusion of virus to the cell/endosome by interfering with the hydrogen bond network in the phospholipid & Lian et al. (2020) \\
\hline Favipiravir & $\begin{array}{l}\text { Destroys the conservative catalytic domain of RNA-dependent RNA polymerase (RdRp), interrupting the nucleotide } \\
\text { incorporation process, thus interfering with the life cycle of the virus }\end{array}$ & Shannon et al. (2020) \\
\hline
\end{tabular}

et al., 2020). But the latter is superior in terms of faster recovery (Chang et al., 2020).

Though Umifenovir did not exhibit severe adverse side effects, gastric problems including digestion, diarrhoea and nausea are reported (Huang et al., 2020). Further, there is no report on nephrotoxicity or hepatotoxicity. But some clinical studies have declared that umifenovir is not effective against SARS-CoV-2 treatment (Huang et al., 2020). Based on a clinical study conducted in Jinyintan Hospital, Wuhan province, it was revealed that Umifenovir neither increases the clearance rate of SARS-CoV-2 nor accelerates the recovery of patients in any way (Lian et al., 2020). The effect of umifenovir in SARS-CoV-2 treatment, still requires clinical investigations for further understanding.

\section{Favipiravir}

Favipiravir was first developed in 2014 by Fujifilm Toyama Chemical Co. Ltd., Japan, for the treatment of a novel influenza strain that was resistant to neuraminidase inhibitors. It is an analogue of guanine with a pyrazine carboxamide structure. Favipiravir enters the infected cell by endocytosis, and at the site it is transformed into favipiravir ribofuranosyl phosphate via phosphoribosylation and phosphorylation. After transformation, the prodrug destroys the conservative catalytic domain of RNA-dependent RNA polymerase (RdRp), interrupting the nucleotide incorporation process, thus interfering with the life cycle of the virus and hindering its replication within the host cell.

The RdRp of SARS-CoV-2 is $10 \mathrm{X}$ more active than any other viral RdRp faced until now (Shanon et al., 2020). Favipiravir is highly recommended as it inhibits viral RNA by sparing the native DNA of the host cell. Chang et al., (2020) conducted a clinical trial on the effectiveness of favipiravir and umifenovir against SARS-CoV-2. The study revealed that the recovery rate in favipiravir was higher than umifenovir. Table 1 shows the mode of action of potential antiviral drugs repurposed for COVID-19.

Treatment with favipiravir causes hyperuricemia. The major adverse effects on use of favipiravir is teratogenicity. Teratogenicity is the phenomenon where some agents (teratogens) cause major birth defects. Thus, the use of favipiravir of women at the child bearing age or pregnant ladies is highly inadvisable. Even men treated with favipiravir are advised to use contraceptive for a week minimum or until favipiravir is out of the system, to avoid any teratogenicity (Evaluation and Licensing Division, Pharmaceutical and Food
Safety Bureau., 2011. Report on the Deliberation Results-Avigan.)

\section{Vaccine Development Approach}

Vaccine development involves different strategies including live attenuated, or inactivated virus, virus-like particles or other protein-based approaches, viral vector-based vaccines or nucleic acid-based vaccines (Chauhan et al., 2020). In live attenuated vaccines, virulence of the virus is removed but viability is retained which in turn helps the immune system to develop memory cells (Badgett et al., 2002). Virus-like particles are molecules that closely resemble viruses which are synthesized by the expression of the viral structural protein. The synthesized molecules can assemble themselves to virus-like particles and help the body to boost immunity (Zeltins 2013). Viral vectorbased vaccines and nucleic acid-based vaccines, incorporate the antibody expressing gene into the cell to produce necessary antibodies to acquire immunity against infections. Drug discovery and development for SARS-CoV-2 can be facilitated by artificial intelligence and other computational tools (Tang et al., 2020b; Lin et al., 2020; Zhou et al., 2020b). Adjuvants such as MF59, AS03, CpG are considered for COVID-19 treatment (Chauhan et al., 2020) to enhance the vaccine efficacy (Weinberger, 2018).

Lipid nanoparticles (Adams et al., 2018), lipid coated mesoporous silica nanoparticles (LaBauve et al., 2018), Macrophage mimetic nanoparticles (MMNPs) (Zhang et al., 2020), Nano-Erythrocyte mimetic drug delivery (Cavezzi et al., 2020; Poduri et al., 2020), Nano-Platelet mimetic drug delivery (Anselmo et al., 2014), Nano-virus mimetic drug delivery (Ellah et al., 2020) have also been considered for COVID-19 therapeutics. The review includes discussion on peptide and nano based vaccine approaches for COVID-19 therapeutics. A complete list of vaccine candidates developed for COVID-19 is given in Supplementary Appendix (WHO-Draft landscape of COVID-19 candidate vaccines, 2021) (Table 4). Figure 2 depicts schematic illustration of vaccine development approach.

\section{Peptide Based Vaccines}

Peptide based vaccines are biologically safe and need not to be produced in vitro. Peptide vaccines outweigh the limitations of conventional vaccines by overcoming allergic reactions and autoimmune responses ( $\mathrm{Li}$ et al., 2014). Peptide based vaccines are engineered to mimic the proteins or peptides in the pathogens, which can help in developing T-cells which are 
TABLE 2 | Peptide based vaccines developed for COVID-19.

\section{Vaccine platform description}

$\mathrm{RBD}$ protein delivered in mannose-conjugated chitosan nanoparticle

Recombinant spike protein with Essai ON 1849101 adjuvant

Peptides

Recombinant spike protein with Essai O/W 1849101 adjuvant

Recombinant S protein

RBD protein (baculovirus production) + FAR-Squalene adjuvant

Protein Subunit

RBD-protein

Recombinant S protein

Peptide + novel adjuvant

S subunit intranasal liposomal formulation with GLA/3M052 adjs.

S-Protein (Subunit) + Adjuvant, E coli based Expression

Protein Subunit S,N,M\&S1 protein

Protein Subunit

RBD protein fused with Fc of IgG + Adj.

Capsid-like Particle

Drosophila S2 insect cell expression system VLPS

Peptide antigens formulated in LNP

$S$ Protein

S Protein + Adjuvant

VLP-recombinant protein + Adjuvant

Microneedle arrays S1 subunit

Peptide

Adjuvanted protein subunit (RBD)

Peptide

S Protein

li-Key peptide

S Protein

Protein Subunit EPV-CoV-19

gp-96 backbone

Subunit vaccine

S1 or RBD protein

Subunit protein, plant produced

Recombinant protein, nanoparticles (based on S-protein and other epitopes)

COVID-19 XWG-03 truncated S proteins

Adjuvanted microsphere peptide

Synthetic Long Peptide Vaccine candidate for S and M proteins

Oral E. coli-based protein expression system of $\mathrm{S}$ and $\mathrm{N}$ proteins

Nanoparticle vaccine

Plant-based subunit (RBD-Fc + Adjuvant)

OMV-based vaccine

OMV-based vaccine

Structurally modified spherical particles of the tobacco mosaic virus (TMV)

Spike-based

Recombinant S1-Fc fusion protein

Recombinant protein

Recombinant S protein in IC-BEVS (Viral vector vaccine (based on baculovirus

expression system in insect cell line)

Orally delivered, heat stable subunit

Peptides derived from Spike protein

Protein Subunit

RBD-based

Outer Membrane Vesicle (OMV)-subunit

Spike-based (epitope screening)

Spiked-based

Recombinant spike with adjuvant

Recombinant S protein produced in BEVS

Protein Subunit Nanoformulated

Protein Subunit Adenoviral Carrier

Protein DC-targeted epitopes

\section{Developers}

Ohio State University/Kazakh National Agrarian University

Kazakh National Agrarian University

Neo7Logic

Kazakh National Agrarian University, Kazakhstan/National Scientific Center for

Especially Dangerous Infections

Max-Planck-Institute of Colloids and Interfaces

Farmacológicos Veterinarios SAC (FARVET SAC)/Universidad Peruana Cayetano

Heredia (UPCH)

Research Institute for Biological Safety Problems, Rep of Kazakhstan

Mynvax

Izmir Biomedicine and Genome Center

Bogazici University

University of Virginia

Helix Biogen Consult, Ogbomoso and Trinity Immonoefficient Laboratory,

Ogbomoso, Oyo State, Nigeria

National Research Centre, Egypt

University of San Martin and CONICET, Argentina

Chulalongkorn University/GPO, Thailand

AdaptVac (PREVENT-nCoV consortium)

Expres2ion

IMV Inc

WRAIR/USAMRIID

National Institute of Infectious Disease, Japan/Shionogi/UMN Pharma

Osaka University/BIKEN/National Institutes of Biomedical Innovation, Japan

Univ. of Pittsburgh

Vaxil Bio

Biological E Ltd.

Flow Pharma Inc

AJ Vaccines

Generex/EpiVax

EpiVax/Univ. of Georgia

Epivax

Heat Biologics/Univ. Of Miami

FBRI SRC VB VECTOR, Rospotrebnadzor, Koltsovo

Baylor College of Medicine

iBio/CC-Pharming

Saint-Petersburg scientific research institute of vaccines and serums

Innovax/Xiamen Univ./GSK

VIDO-InterVac, University of Saskatchewan

OncoGen

MIGAL Galilee Research Institute

LakePharma, Inc.,

Baiya Phytopharm/Chula Vaccine Research Center

Quadram Institute Biosciences

BiOMViS Srl/Univ. of Trento

Lomonosov Moscow State University

University of Alberta

AnyGo Technology

Yisheng Biopharma

Vabiotech, Vietnam and University of Bristol, United Kingdom

Applied Biotechnology Institute, Inc.,

Axon Neuroscience SE

MOGAM Institute for Biomedical Research, GC Pharma

Neovii/Tel Aviv University

Intravacc/Epivax

ImmunoPrecise/LiteVax BV

Nanografi Nano Technology, Middle East Technical University, Ankara University Iran

Tampere University

Vaxinano, CEA, INRAE

CEA, CNRS

LinkinVax, VRI 
TABLE 3 | Nano based therapeutic options for Coronavirus.

\begin{tabular}{|c|c|c|c|c|}
\hline Nanoparticle & Coronavirus antigen & Adjuvant & Mechanism & References \\
\hline $\begin{array}{l}\text { Hollow polymeric } \\
\text { nanoparticles }\end{array}$ & $\begin{array}{l}\text { MERS-CoV (Middle East } \\
\text { Respiratory Syndrome } \\
\text { Coronavirus) }\end{array}$ & STING agonist & $\begin{array}{l}\text { Elicits antigen-specific T-cell response without } \\
\text { triggering eosinophilic immunopathology }\end{array}$ & (Lin et al., 2019) \\
\hline $\begin{array}{l}\text { SARS-S, MERS-S (MERS } \\
\text { Spike protein nanoparticle) }\end{array}$ & SARS-CoV, MERS-CoV & $\begin{array}{l}\text { Amphiphilic membrane } \\
\text { protein aggregates }\end{array}$ & $\begin{array}{l}\text { Production of high levels of neutralizing antibodies in } \\
\text { case of homologous viruses and no response against } \\
\text { heterologous viruses }\end{array}$ & (Coleman et al., 2014) \\
\hline MERS-S & MERS-CoV & Aluminium (alum) & $\begin{array}{l}\text { Simultaneous } T_{\mathrm{H}_{1}} \text { and } \mathrm{T}_{\mathrm{H} 2} \text { response in heterologous } \\
\text { prime-boost }\end{array}$ & (Jung et al., 2020) \\
\hline Gold nanoparticle & SARS-CoV & Gold nanoparticle & Induces strong lgG response & $\begin{array}{l}\text { (Sekimukai, Iwata, } \\
\text { and Shuetsu, 2020) }\end{array}$ \\
\hline Spherical gold nanoparticles & $\begin{array}{l}\text { Transmissible Gastroenteritis } \\
\text { Virus (TGEV) }\end{array}$ & Gold nanoparticle & An increased concentration of Interleukins (ILs) & $\begin{array}{l}\text { (Staroverov et al., } \\
\text { 2019) }\end{array}$ \\
\hline Aluminium nanoparticles & SARS-CoV, MERS-CoV & Alum & $\begin{array}{l}\text { Increase in number of IFN and immunoglobulins, } T_{\mathrm{H} 1} \\
\text { and } T_{\mathrm{H} 2} \text { Balance }\end{array}$ & (Wang N. et al., 2020) \\
\hline
\end{tabular}

immunodominant (Malonis et al., 2020). Synthetic peptide vaccines are usually short amino acid sequences (20-30 amino acids in range) mimicking the specific epitope of the antigen of pathogen. B cells can recognize the mimicked peptide sequence and produce antibodies. T killer cells also kick in fast as the body responds by peptide based vaccine. Antibodies produced during infection target multiple antigen sites and over time some antibodies target specific antigen epitopes for immunity development. Bioinformatics tools facilitate finding the accessible peptide residue sites and a specific peptide can be engineered to bind the site. These tools help to narrow down to SARS-CoV-2-RBD (SARS-CoV-2-Receptor Binding Domain) to interact with hACE2 gaining entry to viral attachment and reentry (Barh et al., 2020; Zhang et al., 2020).

Peptide derived from fermented soy cheese using Lactobacillus delbrueckii WS4 can be used as a potential antiviral agent for SARS CoV-2 (Chourasia et al., 2020). Peptide vaccine developed by IMV Inc., used DPX platform (Ye et al., 2020). Vaxil corporation developed signal peptide ( $\mathrm{Wu}, 2020)$. Epivax and Generex Biotechnology Corporation proposed hybrid based IiKey peptide vaccine (Kallinters et al., 2020). Epivax proposed adjuvating peptide vaccines also ( $\mathrm{Wu}, 2020)$. Table 2 shows the detailed list of peptide based vaccines developed for COVID-19 with platform description and developer.

\section{Nano Based Therapeutic Approaches}

Nanotechnology plays a major role in COVID-19 therapeutics (Petros and DeSimone, 2010). The success of nanotechnology in SARS CoV-2 therapeutics depends on the appropriate choice of nanocarriers for the right drug candidate (Chauhan et al., 2020). Moreover, nanocarriers overcome the limitations of existing antiviral therapies. Nanoparticle aided modulation of antigen presenting cells (APCs) is important for vaccine development in COVID-19 (Banchereau and Steinman 1998; Steinman and Banchereau, 2007). During the initial stages of the COVID-19, nano-macrophage mimetic systems neutralize viral activity and in later stages it reduces the inflammation (Zhang et al., 2020). The effects associated with hematological pathology of COVID19 can be reduced by Nano-Erythrocyte mimetic drug delivery (Cavezzi et al., 2020; Poduri et al., 2020). Thrombocytopenia and vascular damages induced by COVID-19 can be reduced by Nano-Platelet mimetic drug delivery (Anselmo et al., 2014). The self-amplifying RNA encoding SARS-CoV-2 spike protein was encapsulated in lipid nanoparticles which can act as a vaccine for neutralizing the pseudo-virus (Mckay et al., 2020) (Shin et al., 2019). Layered Double Hydroxide (LDH), an inorganic nanoparticle intercalated with short hairpin RNA (shRNA) plasmid has the potential of gene silencing at the target sequence is employed for SARS-CoV-2. Further, it is formulated as a nasal spray for delivering shRNA at the target sites (Acharya, 2020). The small-interfering RNA (si-RNA) encapsulated in lipidic nano-nanoparticles can be used to inhibit chemokine receptor (CCR2), which is responsible for creating cytokine storms. The cytokine storm is one of the major clinical complications in SARS-CoV-2. The inhibition may result in the reduction of inflammatory sites in the infected regions (Campos et al., 2020). Peptide based vaccines are also developed using Lipid nanoparticle formulation. Table 3 shows the nano-based therapeutic options for Coronavirus.

Because of limited side effects, lower dosage quantity and multiple targeting, combination drug therapeutics play a pivotal role in the treatment of COVID-19. Nanocarriers act as potential candidates for multi drug delivery which in turn useful for combination drug therapy (Destache et al., 2009; Shibata et al., 2013). The antigen delivering mode of nanoparticles to dendritic cells facilities T cell immunity (Joffre et al., 2012). Targeted drug delivery for the treatment of COVID-19 can be enhanced by the application of nanomaterials including nanospheres, nanocarriers, liposomes, lipid nanoparticles, nanophages and dendrimers (Witika et al., 2020). Figure 3 depicts the schematic illustration of a nano-based approach to combat COVID-19.

\section{PRESENT STATUS AND FUTURE PERSPECTIVES}

Even though the antimicrobial drugs including chloroquine, remdesivir, lopinavir shows promising results against SARSCoV-2 (Mainardes and Diedrich, 2020), it may cause side 


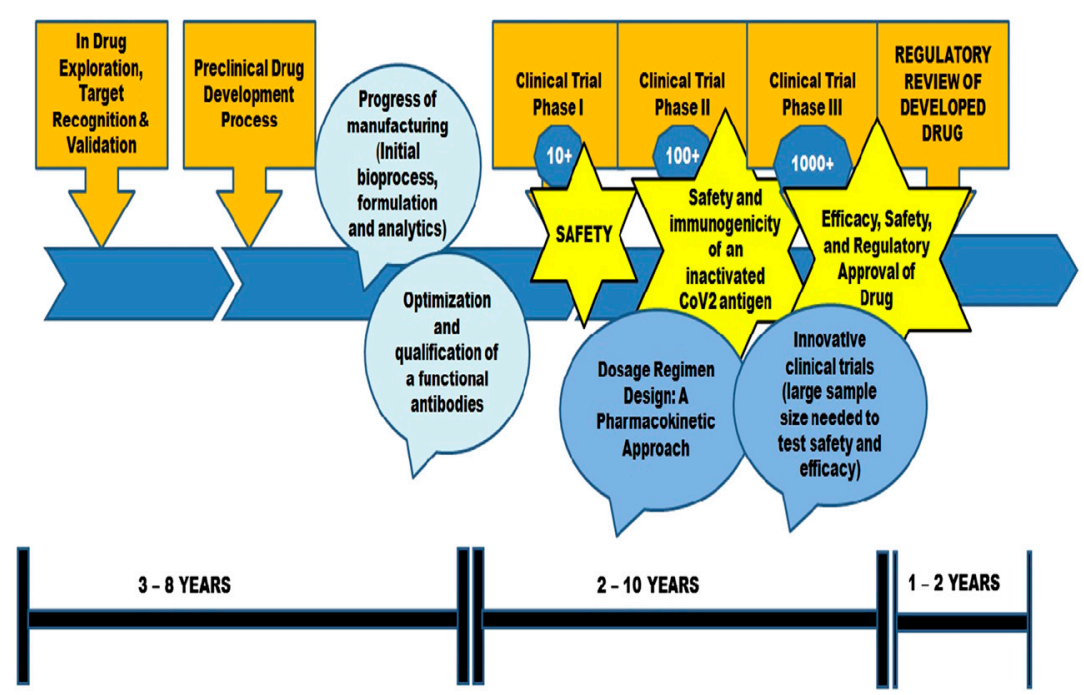

FIGURE 2 | A schematic illustration of vaccine development approach.

effects to some patients. The association of nano-carriers provides a necessary environment for the functioning of these drugs without any harmful effects (Campos et al., 2020). The existing antiviral drugs lack specificity and cause cytotoxicity and which are made to mimic Heparan Sulphate Proteoglycan (HSPG), the first step is virus-cell interaction, which are conserved regions for the ligands of the virus. Unlike invasive carriers, drug delivery of smart nano-carriers is based on the external stimuli like magnetic field or ultrasound (Jindal and Gopinath, 2020). Likewise the effective demonstration of nanocarriers in the treatment of Human Immunodeficiency Virus (HIV), Hepatitis, Influenza A virus etc., (Abd Elkodous et al.,
2019; Negahdari et al., 2019; Kim et al., 2020), the existing drugs are being tested for the treatment of SARS-CoV-2 infection. Since SARS-CoV-2 infects the respiratory system, the drugs are administered through non-invasive methods. The aerosols administered without nano-carriers, may not bind with the target. Hence, nano-carrier mediated drug delivery is preferred for the successful binding with the target (Jindal and Gopinath, 2020).

The iron oxide nanoparticles approved by FDA for in vitro viral treatment was monitored for the discovery of treatment methods of SARS-CoV-2. The docking studies of iron oxide nanoparticles with the viral $S$ protein of the SARS-CoV-2

FIGURE 3 | A schematic illustration of nano-based approach to combat Covid-19.


exhibited better complex binding, which can be further improved in clinical trial stages (Abo-zeid et al., 2020). Several natural compounds have also been contributed to antiviral therapy. The inhibition of Hepatitis $\mathrm{C}$ virus into the hepatoblastoma cells was improved when curcumin loaded chitosan-based nanoparticles are used, it disturbs the viral membrane integrity (Loutfy et al., 2020). The IL-6 and IL-1 $\beta$ mediators of the viral response were diminished when curcumin-based nanoparticles were employed for treating patients with SARS-CoV-2. IL- $1 \beta$ is produced right after viral attachment and IL- 6 on the progression of the infection. It is suggested to use nano-curcumin for COVID-19 (Valizadeh et al., 2020).

The application of silver nanoparticles for the treatment of Respiratory Syncytial Virus (RSV) has shown promising results in the mouse model, in which the nanoparticles tend to inhibit the viral replication in the host by binding to the viral glycoprotein and recruiting the neutrophils. Thus, silver nanoparticles reduce the spread of SARS-CoV-2 and are used to prevent the infected patient from ventilator-associated pneumonia (Morris et al., 2019; Issn and Sarkar 2020; Zachar, 2020). The toxicity caused due to the application of chloroquine and hydroxychloroquine for treating SARS-CoV-2 can be reduced by the application of noble nanoparticles (Au, Ag, Pt) (Rezaee et al., 2020). Currently, novel lipid nanoparticle encapsulates mRNA (mRNA-1273) (NCT04283461) is under clinical trial for SARS-CoV-2 by National Institute of Allergy and Infectious Disease (NIAID), United States. It is also suggested that combination of traditional interventions and western medicine for COVID-19 (Ni et al., 2020). China, Japan, South Korea and Singapore got relieved from the spreading because of Traditional Chinese Medicine (TCM) or Chinese Herbal Medicine (CHM) (Xu and Zhang 2020) and death rate is controlled to considerable extent. Peptide vaccines are considered as the most significant therapeutic compounds for

\section{REFERENCES}

Abd Elkodous, M., El-Sayyad, G. S., Nasser, H. A., Elshamy, A. A., Morsi, M., Abdelrahman, I. Y., et al. (2019). Engineered nanomaterials as potential candidates for HIV treatment: between opportunities and challenges. J. Cluster Sci. 8, 531-540. doi:10.1007/s10876-019-01533-8

Abo-zeid, Y., Ismail, N. S., McLean, G. R., and Hamdy, N. M. (2020). A molecular docking study repurposes FDA approved iron oxide nanoparticles to treat and control COVID-19 infection. Eur. J. Pharm. Sci. 153, 105465. doi:10.1016/j.ejps. 2020.105465

Acharya, R. (2020). Prospective vaccination of COVID-19 using shRNA-plasmid-LDH nanoconjugate. Med. Hypotheses, 143, 110084. doi:10.1016/j.mehy.2020.110084

Adams, D., Gonzalez-Duarte, A., O’Riordan, W. D., Yang, C.- C., Ueda, M., Kristen, A. V., et al. (2018). Patisiran, an RNAi therapeutic, for hereditary transthyretin amyloidosis. N. Engl. J. Med. 379, 11-21. doi:10.1056/nejmoa1716153

Agarwal, G., and Gabrani, R. (2020). Antiviral peptides: identification and validation. Int. J. Pept. Res. Ther. 18, 1-20. doi:10.1007/s10989-020-10072-0

Anselmo, A. C., Modery-Pawlowski, C. L., Menegatti, S., Kumar, S., Vogus, D. R., Tian, L. L., et al. (2014). Platelet-like nanoparticles: mimicking shape, flexibility, and surface biology of platelets to target vascular injuries. ACS Nano. 8, 11243-11253. doi:10.1021/nn503732m

Badgett, M. R., Auer, A., Carmichael, L. E., and Parrish, C. R. (2002). Bull JJ (OctoberEvolutionary dynamics of viral attenuation. J. Virol. 76 (20), 10524-10529. doi:10.1128/jvi.76.20.10524-10529.2002 viral infections (Agarwal and Gabrani, 2020; Brice and Diamond, 2020; Kalita et al., 2020). Further, novel delivery modes facilitate peptides as prominent vaccine candidates for COVID-19 (Di Natale et al., 2020).

\section{CONCLUSION}

WHO is kept on track for the research and development of vaccines against SARS-CoV-2 across the world. Out of all the epidemics and pandemics, the vaccine development has been faster for SARS-CoV-2 due to its fast-paced spread throughout the world. Compared to other SARS virus vaccines that have reached clinical trials within 22 months- 26 months, SARS-CoV2 vaccine is the one in history that has reached the clinical trial phases within 3-6 months. But until an effective vaccine is formulated, it is better to control the pandemic using repurposed drugs.

\section{AUTHOR CONTRIBUTIONS}

KV, PS, VA and MS designed, searched, and analyzed the data and prepared draft figures and tables. KV, PS, DR, MS, prepared the manuscript draft with important intellectual input from $\mathrm{HB}$, SR, KA, PB, CB, AP, KB and MS All authors approved the final manuscript.

\section{SUPPLEMENTARY MATERIAL}

The Supplementary Material for this article can be found online at: https://www.frontiersin.org/articles/10.3389/fmolb.2021.604447/ full\#supplementary-material.

Banchereau, J., and Steinman, R. M. (1998). Dendritic cells and the control of immunity. Nature 392, 245-252. doi:10.1038/32588

Barh, D., Tiwari, S., Silva Andrade, B., Giovanetti, M., Almeida Costa, E., and Kumavath, R. (2020). Potential chimeric peptides to block the SARS-CoV-2 spike receptor-binding domain. F1000Res 9, 576. doi:10.12688/f1000research.24074.1

Beigel, J. H., Tomashek, K. M., Dodd, L. E., Mehta, A. K., Zingman, B. S., Kalil, A. C., et al. (2020). Remdesivir for the treatment of COVID-19-preliminary report. $N$. Engl. J. Med. 383 (10), 993-994. doi:10.1056/NEJMc2022236

Borba, M., Val, F., Sampaio, V. S., Alexandre, M., Melo, G. C., Brito, M., et al. Cloro Covid-19 Team (2020). Effect of high vs low doses of chloroquine diphosphate as adjunctive therapy for patients hospitalized with severe acute respiratory syndrome coronavirus 2 (SARS-CoV-2) infection: a randomized clinical trial. JAMA Netw. Open 3 (4), e208857.

Brice, D. C., and Diamond, G. (2020). Antiviral activities of human host defense peptides. Curr. Med. Chem. 27 (9), 1420-1443. doi:10.2174/ 0929867326666190805151654

Campos, E. V. R., Pereira, A. E. S., de Oliveira, J. L., Carvalho, L. B., GuilgerCasagrande, M., de Lima, R., et al. (2020). How can nanotechnology help to combat COVID-19? opportunities and urgent need. J. Nanobiotechnol. 18, 1-23. doi:10.1186/s12951-020-00685-4

Cao, B., Wang, Y., Wen, D., Liu, W., Wang, J., Fan, G., et al. (2020). A trial of lopinavir-ritonavir in adults hospitalized with severe covid-19. N. Engl. J. Med. 382 (19), 1787-1799. doi:10.1056/NEJMoa2001282

Cao, X. (2020). COVID-19: immunopathology and its implications for therapy. Nat. Rev. Immunol. 2020, 1-2. doi:10.1038/s41577-020-0308-3 
Cavezzi, A., Troiani, E., and Corrao, S. (2020). COVID-19: hemoglobin, iron, and hypoxia beyond inflammation. A narrative review. Clin. Pract. 10, 1271. doi:10. 4081/cp.2020.1271

Chakravarthy, M., and Vora, A. (2020). Nanotechnology based antiviral therapeutics. Drug Deliv. Transl. Res. 2020, 1-40. doi:10.1007/s13346-02000818-0

Chang, C., Yi, Z., Jianying, H., Ping, Y., Zhenshun, C., Jianyuan, W., et al. (2020). Favipiravir versus arbidol for COVID-19: a randomized clinical trial. medRxiv 2020, 20037432. doi:10.1101/2020.03.17.20037432v4

Chauhan, G., Madou, M. J., Kalra, S., Chopra, V., Ghosh, D., Martinez-Chapa, S. O., et al. (2020). Nanotechnology for COVID-19: therapeutics and vaccine research. ACS Nano. 14 (7), 7760-7782. doi:10.1021/acsnano.0c04006

Chen, N., Zhou, M., Dong, X., Qu, J., Gong, F., Han, Y., et al. (2020). Epidemiological and clinical characteristics of 99 cases of 2019 novel coronavirus pneumonia in Wuhan, China: a descriptive study. Lancet 395 (10223), 507-513. doi:10.1016/s0140-6736(20)30211-7

Chourasia, R., Padhi, S., Chiring Phukon, L., Abedin, M. M., Singh, S. P., and Rai, A. K. (2020). A potential peptide from soy cheese produced using Lactobacillus delbrueckii WS4 for effective inhibition of SARS-CoV-2 main protease and S1 glycoprotein. Front. Mol. Biosci. 7, 601753. doi:10. 3389/fmolb.2020.601753

Coleman, C. M., Liu, Y. V., Mu, H., Taylor, J. K., Massare, M., Flyer, D. C., et al. (2014). Purified coronavirus spike protein nanoparticles induce coronavirus neutralizing antibodies in mice. Vaccine 32 (26), 3169-3174. doi:10.1016/j. vaccine.2014.04.016

Deng, L., Li, C., Zeng, Q., Liu, X., Li, X., Zhang, H., et al. (2020). Arbidol combined with LPV/r versus LPV/r alone against Corona Virus Disease 2019: a retrospective cohort study. J. Infect. 81 (1), e1-e5. doi:10.1016/j.jinf.2020.03.002

Destache, C. J., Belgum, T., Christensen, K., Shibata, A., Sharma, A., and Dash, A. (2009). Combination antiretroviral drugs in PLGA nanoparticle for HIV-1. BMC Infect. Dis. 9, 198. doi:10.1186/1471-2334-9-198

Di Natale, C., La Manna, S., De Benedictis, I., Brandi, P., and Marasco, D. (2020). Perspectives in peptide-based vaccination strategies for syndrome coronavirus 2 pandemic. Front. Pharmacol. 11, 578382. doi:10.3389/fphar.2020.578382

Ellah, N. H. A., Gad, S. F., Muhammad, K., Batiha, G. E., and Hetta, H. F. (2020). Nanomedicine as a promising approach for diagnosis, treatment and prophylaxis against COVID-19. Nanomedicine 15, 2085-2102. doi:10.2217/nnm-2020-0247

Fan, Q., Zhang, B., Ma, J., and Zhang, S. (2020). Safety profile of the antiviral drug remdesivir: an update. Biomed. Pharmacother. 130, 110532. doi:10.1016/j. biopha.2020.110532

Gordon, C. J., Tchesnokov, E. P., Woolner, E., Perry, J. K., Feng, J. Y., Porter, D. P., et al. (2020). Remdesivir is a direct-acting antiviral that inhibits RNAdependent RNA polymerase from severe acute respiratory syndrome coronavirus 2 with high potency. J. Biol. Chem. 295 (20), 6785-6797. doi:10. 1074/jbc.RA120.013679

Guan, W.-J., Ni, Z.-Y., Hu, Y., Liang, W.-H., Ou, C.-Q., He, J.-X., et al. (2020). Clinical characteristics of coronavirus disease 2019 in China. N. Engl. J. Med. 382, 1708-1720. doi:10.1056/NEJMoa2002032

Huang, D., Yu, H., Wang, T., Yang, H., Yao, R., and Liang, Z. (2020). Efficacy and safety of umifenovir for coronavirus disease 2019 (COVID-19): a systematic review and meta-analysis. J. Med. Virol. 93, 481. doi:10.1002/jmv.26256

Issn, O. P., and Sarkar, S. (2020). Silver nanoparticles with bronchodilators through nebulisation to treat COVID 19 patients. J. Curr. Med. Res. Opi. 3 (4), 449-450. doi:10.15520/jcmro.v3i04.276

Jindal, S., and Gopinath, P. (2020). Nanotechnology based approaches for combatting COVID-19 viral infection. Nano. Express. 1 (2), 022003. doi:10. 1088/2632-959x/abb714

Joffre, O. P., Segura, E., Savina, A., and Amigorena, S. (2012). Cross-presentation by dendritic cells. Nat. Rev. Immunol. 12, 557-569. doi:10.1038/nri3254

Joint Formulary Committee (2020). British national formulary 2020. Available at: http://www.medicinescomplete.com (Accessed April 03, 2020).

Jung, S., et al. (2020). Since January 2020 Elsevier has created a COVID-19 resource centre with free information in English and Mandarin on the novel coronavirus COVID- 19. The COVID-19 resource centre is hosted. Elsevier connect, the company's public news and information, January.

Juurlink, D. N. (2020). Safety considerations with chloroquine, hydroxychloroquine and azithromycin in the management of SARS-CoV-2 infection. CMAJ 192 (17), E450-E453. doi:10.1503/cmaj.200528
Kalita, P., Padhi, A. K., Zhang, K. Y. J., and Tripathi, T. (2020). Design of a peptidebased subunit vaccine against novel coronavirus SARS-CoV-2. Microb. Pathog. 145, 104236. doi:10.1016/j.micpath.2020.104236

Kallinteris, N. L., Lu, X., Blackwell, C. E., von Hofe, E., Humphreys, R. E., and Xu, M. (2006). Ii-Key/MHC class II epitope hybrids: a strategy that enhances MHC class II epitope loading to create more potent peptide vaccines. Expert Opin. Biol. Ther. 6 (12), 1311-1321. doi:10.1517/14712598.6.12.1311

Kim, Y. C., Dema, B., and Reyes-Sandoval, A. (2020). COVID-19 vaccines: breaking record times to first-in-human trials. NPJ Vaccin. 5, 34. doi:10. 1038/s41541-020-0188-3

LaBauve, A. E., Rinker, T. E., Noureddine, A., Serda, R. E., Howe, J. Y., Sherman, M. B., et al. (2018). Lipid-coated mesoporous silica nanoparticles for the delivery of the ML336 antiviral to inhibit encephalitic alphavirus infection. Sci. Rep. 8, 13990. doi:10.1038/s41598-018-32033-w

Li, W., Joshi, M., Singhania, S., Ramsey, K., and Murthy, A. (2014). Peptide vaccine: progress and challenges. Vaccines (Basel) 2 (3), 515-536. doi:10.3390/ vaccines 2030515

Lian, N., Xie, H., Lin, S., Huang, J., Zhao, J., and Lin, Q. (2020). Umifenovir treatment is not associated with improved outcomes in patients with coronavirus disease 2019: a retrospective study. Clin. Microbiol. Infect. 26, 917-921. doi:10.1016/j.cmi.2020.04.026

Lin, L. C. W., Huang, C. Y., Yao, B. Y., Lin, J. C., Agrawal, A., Algaissi, A., et al. (2019). Viromimetic STING agonist-loaded hollow polymeric nanoparticles for safe and effective vaccination against Middle East respiratory syndrome coronavirus. Adv. Funct. Mater. 29 (28), 18076161. doi:10.1002/adfm.201807616

Lin, S. M., Lin, S. C., Hsu, J. N., Chang, C. K., Chien, C. M., Wang, Y. S., et al. (2020). Structure-based stabilization of non-native protein-protein interactions of coronavirus nucleocapsid proteins in antiviral drug design. J. Med. Chem. 63, 3131-3141. doi:10.1021/acs.jmedchem.9b01913

Liu, J., Cao, R., Xu, M., Wang, X., Zhang, H., Hu, H., et al. (2020). Hydroxychloroquine sulfate monograph for professionals'. The American society of health-system pharmacists. 20 March 2020. Hydroxychloroquine, a less toxic derivative of chloroquine, is effective in inhibiting SARS-CoV-2 infection in vitro. Cel Discov. 6, 16. doi:10.1038/s41421-020-0156-0

Liu, X., and Wang, X. J. (2020). Potential inhibitors against 2019-nCoV coronavirus $\mathrm{M}$ protease from clinically approved medicines. J. Genet. Genomics 47 (2), 119-121. doi:10.1016/j.jgg.2020.02.001

Lo, M. K., Jordan, R., Arvey, A., Sudhamsu, J., Shrivastava-Ranjan, P., Hotard, A. L., et al. (2017). GS-5734 and its parent nucleoside analog inhibit Filo-, Pneumo-, and Paramyxoviruses. Sci. Rep. 7, 43395. doi:10.1038/srep43395

Loutfy, S. A., Elberry, M. H., and Ibrahim, A. H. (2020). Antiviral activity of chitosan nanoparticles encapsulating curcumin against hepatitis C virus genotype $4 \mathrm{a}$ in human hepatoma cell lines. Int. J. Nanomedicine. 15, 2699-2715. doi:10.2147/IJN.S241702

Mainardes, R. M., and Diedrich, C. (2020). The potential role of nanomedicine on COVID-19 therapeutics. Therap. Deliv. 7-9. doi:10.4155/tde-2020-0069

Malonis, R. J., Lai, J. R., and Vergnolle, O. (2020). Peptide-based vaccines: current progress and future challenges. Chem. Rev. 120 (6), 3210-3229. doi:10.1021/acs. chemrev.9b00472

Mckay, P. F., Hu, K., Blakney, A. K., Samnuan, K., Bouton, C. R., Rogers, P., et al. (2020). Self-amplifying RNA SARS-CoV-2 lipid nanoparticle vaccine induces equivalent preclinical antibody titers and viral neutralization to recovered COVID-19 patients. Nat. Comm. 11, 1-14. doi:10.1101/2020.04.22.055608v1

Morris, D., Ansar, M., Speshock, J., Ivanciuc, T., Qu, Y., Casola, A., et al. (2019). Antiviral and immunomodulatory activity of silver nanoparticles in experimental RSV infection. Viruses 11 (8), 732. doi:10.3390/v11080732

Negahdari, B., Darvishi, M., and Saeedi, A. A. (2019). Gold nanoparticles and hepatitis B virus. Artif. Cells Nanomed. Biotechnol. 47 (1), 469-474. doi:10.1080/ 21691401.2018.1546185

Ni, L., Zhou, L., Zhou, M., Zhao, J., and Wang, D. W. (2020). Combination of western medicine and Chinese traditional patent medicine in treating a family case of COVID-19. Front. Med. 14 (2), 210-214. doi:10.1007/s11684-020-0757-x

Petros, R. A., and DeSimone, J. M. (2010). Strategies in the design of nanoparticles for therapeutic applications. Nat. Rev. Drug Discov. 9, 615-627. doi:10.1038/nrd2591

Pharmaceuticals and Medical Devices Agency (2011). Evaluation and licensing division, pharmaceutical and Food safety BureauReport on the deliberation results-avigan. Japan Available at: www.pmda.go.jp/ files/000210319.pdf. 
Poduri, R., Joshi, G., and Jagadeesh, G. (2020). Drugs targeting various stages of the SARS-CoV-2 life cycle: exploring promising drugs for the treatment of Covid19. Cell. Signal. 74, 109721. doi:10.1016/j.cellsig.2020.109721

Rezaee, P., Akbari, M., Morad, R., Koochaki, A., Maaz, M., and Jamshidi, Z. (2020). First principle simulation of coated hydroxychloroquine on $\mathrm{Ag}, \mathrm{Au}$ and $\mathrm{Pt}$ nanoparticle as a potential candidate for treatment of SARS-CoV-2 (COVID19). arXiv. arXiv:2006.02343.

Rismanbaf, A., and Zarei, S. (2020). Liver and kidney injuries in COVID-19 and their effects on drug therapy; a letter to editor. Arch. Acad. Emerg. Med. 8 (1), e17. doi:10.22037/aaem.v8i1.590

Saha, A., Sharma, A. R., Bhattacharya, M., Sharma, G., Lee, S. S., and Chakraborty, C. (2020). Probable molecular mechanism of Remdesivir for the treatment of COVID-19: need to know more. Arch. Med. Res. 51 (6), 585-586. doi:10.1016/j. arcmed.2020.05.001

Sekimukai, H., Iwata, N., and Shuetsu, Y. (2020). Gold nanoparticle-adjuvanted S protein induces a strong antigen-specific IgG response against severe acute respiratory syndrome-related coronavirus infection, but fails to induce protective antibodies and limit eosinophilic infiltration in lungs. Microbiol. Immunol. 64, 33-51. doi:10.1111/1348-0421.12754

Shannon, A., Selisko, B., Le, N., Huchting, J., Touret, F., Piorkowski, G., et al. (2020). Favipiravir strikes the SARS-CoV-2 at its Achilles Heel, the RNA polymerase. bioRxiv: preprint Server Biol. doi:10.1101/2020.05.15.098731

Shibata, A., McMullen, E., Pham, A., Belshan, M., Sanford, B., Zhou, Y., et al. (2013). Polymeric nanoparticles containing combination antiretroviral drugs for HIV type 1 treatment. AIDS Res. Hum. Retroviruses 29, 746-754. doi:10.1089/aid.2012.0301

Shin, M. D., Shukla, S., Chung, Y. H., Beiss, V., Chan, S. K., Ortega-Rivera, O. A., et al. (2020). COVID-19 vaccine development and a potential nanomaterial path forward. Nat. Nanotechnol. 15 (8), 646-655. doi:10.1038/s41565-020$0737-y$

Staroverov, S. A., Volkov, A. A., Mezhenny, P. V., Domnitsky, I. Y., Fomin, A. S., Kozlov, S. V., et al. (2019). Prospects for the use of spherical gold nanoparticles in immunization. Appl. Microbiol. Biotechnol. 103, 437-447. doi:10.1007/ s00253-018-9476-5

Steinman, R. M., and Banchereau, J. (2007). Taking dendritic cells into medicine. Nature 449, 419-426. doi:10.1038/nature06175

Tahir ul Qamar, M., Alqahtani, S. M., Alamri, M. A., and Chen, L.-L. (2020). Structural basis of SARS-CoV-2 3CLpro and anti-COVID-19 drug discovery from medicinal plants. J. Pharm. Anal. 10, 313. doi:10.1016/j.jpha.2020. 03.009

Tang, W., Cao, Z., Han, M., Wang, Z., Chen, J., Sun, W., et al. (2020a). Hydroxychloroquine in patients with COVID-19: an open-label, randomized control trial. medRxiv. doi:10.1101/2020.04.10.20060558

Tang, B., He, F., Liu, D., Fang, M., Wu, Z., and Xu, D. (2020b). AI-aided design of novel targeted covalent inhibitors against SARS-CoV-2. bioRxiv. (Accessed April 07, 2020). doi:10.1101/2020.03.03.972133

Valizadeh, H., Abdolmohammadi-Vahid, S., Danshina, S., Gencer, M. Z., Ammari, A., Sadeghi, A., et al. (2020). Nano-curcumin therapy, a promising method in modulating inflammatory cytokines in COVID-19 patients. Int. Immunopharmacology 89, 107088. doi:10.1016/j.intimp.2020.107088

Velavan, T. P., and Meyer, C. G. (2020). The COVID-19 epidemic. Trop. Med. Int. Health 25 (3), 278-280. doi:10.1111/tmi.13383 Available at: https://pubmed. ncbi.nlm.nih.gov/32052514/.

Villalaín, J. (2010). Membranotropic effects of arbidol, a broad anti-viral molecule, on phospholipid model membranes. J. Phys. Chem. B 114 (25), 8544-8554. doi:10.1021/jp102619w

Wang, M., Cao, R., Zhang, L., Yang, X., Liu, J., Xu, M., et al. (2020). Remdesivir and chloroquine effectively inhibit the recently emerged novel coronavirus (2019$\mathrm{nCoV}$ ) in vitro. Cell Res. 30 (3), 269-271. doi:10.1038/s41422-020-0282-0

Wang, N., Wei, C., Zhang, Z., Liu, T., and Wang, T. (2020). Aluminum nanoparticles acting as a pulmonary vaccine adjuvant-delivery system (VADS) able to safely elicit robust systemic and mucosal immunity. J. Inorg. Organomet. Polym. 30, 4203-4217. doi:10.1007/s10904-020-01572-z
Wang, W., J., W., Zhao, X., Zai, J., and Li, X. (2020). Homologous recombination within the spike glycoprotein of the newly identified coronavirus may boost cross-species transmission from snake to human. J. Med. Virol. 92.

Weinberger, B. (2018). Adjuvant strategies to improve vaccination of the elderly population. Curr. Opin. Pharmacol. 41, 34-41. doi:10.1016/j.coph.2018.03.014

WHO-Draft landscape of COVID-19 candidate vaccines (2021). WHO-Draft landscape of COVID-19 candidate vaccines. Available at: https://www.who. int/publications/m/item/draft-landscape-of-covid-19-candidate-vaccines.

Williamson, B. N., Feldmann, F., Schwarz, B., Meade-White, K., Porter, D. P., Schulz, J., et al. (2020). Clinical benefit of remdesivir in rhesus macaques infected with SARS-CoV-2. bioRxiv. doi:10.1101/2020.04.15.043166

Wit, E. (2020). Clinical benefit of remdesivir in rhesus macaques infected with SARS-CoV-2. Nature 585 (7824), 273-276. doi:10.1038/s41586-020-2423-5

Witika, B. A., Makoni, P. A., Mweetwa, L. L., Ntemi, P. V., M. T. , R., Mwila, S. K. C., et al. (2020). Nano-biomimetic drug delivery vehicles: potential approaches for COVID-19 treatment. Molecules 25, 5952. doi:10.3390/molecules25245952

Wrapp, D., Wang, N., Corbett, K. S., Goldsmith, J. A., Hsieh, C. L., Abiona, O., et al (2020). Cryo-EM structure of the 2019-nCoV spike in the prefusion conformation. Science 367 (6483), 1260-1263. doi:10.1126/science.abb2507

Wu, S. C. (2020). Progress and concept for COVID-19 vaccine development. Biotechnol. J. 15 (6), e2000147. doi:10.1002/biot.202000147

$\mathrm{Xu}$, J., and Zhang, Y. (2020). Traditional Chinese medicine treatment of COVID19. Complement. Ther. Clin. Pract. 39, 101165. doi:10.1016/j.ctcp.2020.101165

Ye, T., Zhong, Z., García-Sastre, A., Schotsaert, M., and De Geest, B. G. (2020). Current status of COVID-19 (pre) clinical vaccine development. Angew. Chem. Int. Ed. Engl. [Epub ahead of print]. doi:10.1002/anie.202008319

Zachar, O. (2020). Formulations for COVID-19 early stage treatment via silver nanoparticles inhalation delivery at home and hospital. Scie.Open Pre. 2020, 0-3. doi:10.14293/S2199-1006.1.SOR-.PPHBJEO.v1

Zeltins, A. (2013). Construction and characterization of virus-like particles: a review. Mol. Biotechnol. 53 (1), 92-107. doi:10.1007/s12033-012-9598-4

Zhang, Q., Honko, A., Zhou, J., Gong, H., Downs, S. N., Vasquez, J. H., et al. Cellular nanosponges inhibit SARS-CoV-2 infectivity. Nano Lett. 2020, 20, 5570-5574. doi:10.1021/acs.nanolett.0c02278

Zhou, P., Yang, X. L., Wang, X. G., Hu, B., Zhang, L., and Zhang, W. (2020). A pneumonia outbreak associated with a new coronavirus of probable bat origin. Nature 579 (7798), 270-273. doi:10.1038/s41586-020-2012-7

Zhang, G., Pomplun, S., Loftis, A. R., Loas, A., and Pentelute, B. L. (2020). The firstin-class peptide binder to the SARS-CoV-2 spike protein. bioRxiv. doi:10.1101/ 2020.03.19.999318

Zhou, Y., Hou, Y., Shen, J., Huang, Y., Martin, W., and Cheng, F. (2020a). Networkbased drug repurposing for novel coronavirus 2019-nCoV/SARS-CoV-2. $\mathrm{Cel}$ Discov. 6, 1-18. doi:10.1038/s41421-020-0153-3

Zhou, Y., Wang, F., Tang, J., Nussinov, R., and Cheng, F. (2020b). Artificial intelligence in COVID-19 drug repurposing. Lancet Digit. Health. 2 (5), e667-e676. doi:10.1016/S2589-7500(20)30192-8

Zumla, A., Chan, J. F., Azhar, E. I., Hui, D. S., and Yuen, K. Y. (2016). Coronaviruses - drug discovery and therapeutic options. Nat. Rev. Drug Discov. 15 (5), 327-347. doi:10.1038/nrd.2015.37

Conflict of Interest: The authors declare that the research was conducted in the absence of any commercial or financial relationships that could be construed as a potential conflict of interest.

Copyright $\odot 2021$ Vivekanandhan, Shanmugam, Barabadi, Arumugam, Daniel Raj Daniel Paul Raj, Sivasubramanian, Ramasamy, Anand, Boomi, Chandrasekaran, Arokiyaraj and Saravanan. This is an open-access article distributed under the terms of the Creative Commons Attribution License (CC BY). The use, distribution or reproduction in other forums is permitted, provided the original author(s) and the copyright owner(s) are credited and that the original publication in this journal is cited, in accordance with accepted academic practice. No use, distribution or reproduction is permitted which does not comply with these terms. 